УДК 37.013 .42

DOI 10.37386/2413-4481-2021-2-18-22

\title{
О.П. Кикоть
}

Бийский промышленно-технологический колледж, г. Бийск, Россия

Е.Б. Манузина

Алтайский государственный гуманитарно-педагогический университет им. В.М. Шукшина, г. Бийск, Россия

\section{Е.Г. Новолодская}

Алтайский государственный гуманитарно-педагогический университет им. В.М. Шукшина, г. Бийск, Россия

\section{УПРАВЛЕНИЕ ДЕЯТЕЛЬНОСТЬЮ ОБРАЗОВАТЕЛЬНЫХ ОРГАНИЗАЦИЙ, РАБОТАЮЩИХ В СЛОЖНЫХ СОЦИАЛЬНЫХ УСЛОВИЯХ}

\begin{abstract}
В статье раскрыты особенности управления деятельностью школ, функционирующих в неблагоприятных социальных условиях, дана характеристика образовательных организаций, демонстрирующих низкие образовательные результаты, представлена качественная оценка ресурсов и факторов, оказывающих влияние на достижения школьников и эффективность деятельности школ, предложена программа управления деятельностью общеобразовательных организаций по переводу в эффективный режим функционирования, описаны результаты ее внедрения.

Ключевые слова: качество образования, низкие образовательные результаты, образовательные организации, функционирующие в неблагоприятных социальных условиях, образовательные дефициты, диагностика образовательных дефицитов.
\end{abstract}

\section{O.P. Kikot}

Biysk Industrial and Technological College, Biysk, Russia

E.B. Manuzina

Shukshin Altai State University for Humanities and Pedagogy, Biysk, Russia

E.G. Novolodskaya

Shukshin Altai State University for Humanities and Pedagogy, Biysk, Russia

\section{MANAGEMENT OF THE ACTIVITIES OF EDUCATIONAL INSTITUTIONS WORKING IN HARD SOCIAL CONDITIONS}

\begin{abstract}
The article reveals the features of managing the activities of schools operating in unfavorable social conditions, gives a characteristic of educational institutions that show low academic results, presents a qualitative assessment of the resources and factors that affect the students' performance and the efficiency of schools, proposes a program for managing the activities of educational institutions in order to transfer them to the effective mode of operation, the results of its implementation are described.

Key words: quality of education, low academic results, educational institutions operating in unfavorable social conditions, academic deficiency diagnosis.
\end{abstract}

Государственная политика в области образования в Российской Федерации обусловлена необходимостью перехода к демократическому и правовому государству. Важную роль в решении этой задачи играет обеспечение качества образования, базирующегося на сохранении его фундаментальности, соответствующего актуальным запросам современной жизни, потребностям личности, общества и государства.

Как отмечает С.С. Кравцов, национальный проект «Образование», как инструмент реализа- ции государственной политики в образовании, направлен на поддержку «точек роста». Условия, созданные для позитивной реализации образовательной политики, и долговременные тенденции «точек роста» лидеров образования должны способствовать тому, что сегмент сектора образования высокого качества расширится и станет драйвером для системы в целом [1].

Однако экономические и социальные условия последних лет внесли свои коррективы в развитие системы российского образования. С одной сто- 
роны, для системы образования актуальным является сохранение ее базовых достижений, создающих гарантии гражданам страны в получении доступного и качественного образования [2]. С другой стороны, важным трендом социальной сферы в последние годы стал рост неравенства в доступе к образовательным услугам высокого качества [3].

Современные педагогические исследования демонстрируют тенденцию сохранения образовательных организаций с низкими образовательными результатами, которые функционируют в неблагоприятных социальных условиях, расположены в отдаленных территориях, имеют дефицит кадровых и материальных ресурсов и др. Но президент России В.В. Путин в статье «Строительство справедливости. Социальная политика для России» указывает, что «если школы работают в трудных социальных условиях, то и они, а не только гимназии и лицеи, работающие, как правило, с благополучными детьми, должны получать специальную поддержку: методическую, кадровую и финансовую» [4].

Обозначенные реалии и противоречия позволили нам определить проблему необходимости разработки системы управления деятельностью образовательных организаций, функционирующих в неблагоприятных социальных условиях, которая позволит определить оптимальную стратегию ее развития. Исследованиями в данной области занимались С.С. Кравцов, С.Г. Косарецкий, Н.А. Крутий, Е.Б. Манузина, М.А. Пинская, К.М. Ушаков, И.Д. Фрумин, А.Г. Уваров, Г.А. Ястребов и др. [3, 5-8].

Теоретический анализ исследований по указанной проблеме позволил нам сделать следующие выводы:

- школы, работающие в менее благоприятных социальных условиях, обладающие недостаточно компетентным кадровым составом и незначительными материальными ресурсами, имеют меньше шансов достичь высоких показателей (часть таких школ, которые можно считать наиболее неблагополучными, устойчиво демонстрирует низкие учебные достижения);

- существует определенная региональная специфика, в соответствии с которой меняется доля неблагополучных школ в общем массиве образовательных учреждений региона и их преимущественная территориальная принадлежность;

- наиболее общими характеристиками школ с устойчиво низкими учебными результатами являются сложный контингент учащихся (дети безработных родителей, родителей с низким уровнем образования, ученики с девиантным поведением, с неродным русским языком и пр.) и ограниченные ресурсы (кадровые и финансовые);

- школы, находящиеся в сложных социальных контекстах, могут обеспечивать обучающимся достаточно высокий уровень достижений, не проигрывая более благополучным образовательным организациям, если последовательно и системно реализуют образовательные стратегии, обеспечивающие эффективный режим работы;

- переход на более эффективный режим работы требует от школы системных усилий и должен быть обеспечен соответствующей поддержкой на муниципальном и региональном уровнях.

На основе анализа теоретических исследований была организована опытно-экспериментальная работа, целью которой являются теоретическое обоснование, реализация и экспериментальная проверка эффективности системы управления деятельностью образовательных организаций, работающих в сложных социальных условиях, по переводу в эффективный режим функционирования.

Для достижения обозначенной цели нами были сформулированы следующие задачи:

- провести оценку различий ресурсов, образовательных результатов школ, качественную оценку факторов, оказывающих влияние на достижения школьников и эффективность школ в соответствии с уровнем результативности;

- разработать и апробировать программу управления деятельностью образовательных организаций, работающих в сложных социальных условиях, по переводу в эффективный режим функционирования и проверить ее эффективность.

Эмпирическое исследование проводилось на базе 24 общеобразовательных организаций муниципальной системы образования города Бийска Алтайского края. В исследовании использовался метод статистического анализа кадровых, материально-технических условий, результатов независимых оценочных процедур ОГЭ (9-й класс), ЕГЭ (11-й класс), контекстных характеристик школ.

На первом этапе был проведен анализ данных о деятельности образовательных организаций, функционирующих в сложных социальных условиях на уровне муниципалитета:

- определена динамика учебных достижений обучающихся по результатам ОГЭ и ЕГЭ за три года;

- проанализированы кадровые условия и материально-техническое оснащение общеобразовательных организаций;

- сформированы аналитические данные по контингенту обучающихся и социальному статусу их семей; 
- установлено влияние социально-экономических условий общеобразовательных организаций на результаты обучения.

Проведенное диагностическое исследование позволило сделать следующие выводы:

1. Анализируя общий массив школ города, можно выделить общеобразовательные организации, стабильно демонстрирующие высокие и средние результаты по определенным показателям и критериям, а также школы, показывающие стабильно низкие образовательные результаты. Общеобразовательные организации с высокими результатами имеют благоприятный контекст, социально-экономические условия, высококвалифицированный кадровый состав и достаточное материально-техническое обеспечение. Как правило, к таким учреждениям относятся гимназии, средние общеобразовательные школы с углубленным изучением отдельных предметов и общеобразовательные школы с численностью более 1000 обучающихся.

2. Для школ, демонстрирующих низкие образовательные результаты, характерны следующие проблемы:

- дефицит кадров (отсутствие достаточного количества квалифицированных педагогов);

- технический уровень оснащения ниже среднего;

- низкий уровень социального контекста (относятся к группе неблагополучных школ).

3. Одной из главных характеристик школ с низкими образовательными результатами является контингент обучающихся:

- количество учеников, состоящих на различных видах профилактического учета;

- количество учащихся, проживающих в семьях, где работает один из родителей или родители безработные;

- количество детей и подростков из семей, находящихся в социально-опасном положении.

Однако общеобразовательные организации, находящиеся в сложных социальных условиях, имеют возможность создавать среду для формирования у обучающихся успешной траектории развития при условии, что данная деятельность будет реализовываться в рамках образовательной стратегии деятельности школы. Эта целенаправленная деятельность должна стать основой для разработки программы повышения качества функционирования школы при поддержке на муниципальном и региональном уровнях.

На следующем этапе были внесены изменения в управление деятельностью образовательных организаций, работающих в сложных социальных условиях, по переводу в эффективный режим функционирования. Для достижения обозначенной перспективы были определены следующие направления деятельности:

- создание условий для улучшения качества управления - стратегических команд школ во главе с эффективным лидером;

- разработка системы мер по повышению уровня образовательных достижений учеников, включая системный мониторинг и коррекцию реализуемых мероприятий;

- создание условий для становления «эффективного учителя» с высоким уровнем профессиональной мотивации, владеющего результативными технологиями и практиками обучения и воспитания, нацеленного на повышение жизненных перспектив всех обучающихся;

- совершенствование системы социально-психологической службы и психолого-педагогического сопровождения учащихся, имеющих низкие образовательные результаты и находящихся в трудной жизненной ситуации.

Для решения прикладных задач была разработана программа управления деятельностью образовательных организаций, работающих в сложных социальных условиях, по переводу в эффективный режим функционирования. Разработка программы обусловлена потребностью в эффективных механизмах и инструментариях, обеспечивающих достижение комплекса позитивных образовательных результатов в школах города Бийска, находящихся в группе риска и нуждающихся в поддержке.

В программу управления деятельностью образовательных организаций, работающих в сложных социальных условиях, были включены компоненты:

- проведение самообследования и идентификации школ с низкими образовательными результатами и находящихся в сложных социальных условиях;

- формирование в данных школах управляющих команд, возлагающих на себя ответственность за разработку и реализацию школьной программы улучшения учебных результатов (в данную команду наряду с директором входят руководители среднего уровня: заместители директора, руководители образовательных программ и предметных объединений, члены управляющего совета);

- определение возможных партнеров и консультантов школ, включая муниципальных сетевых консультантов;

- повышение квалификации руководителей по эффективному управлению (педагогическое лидерство, распределенное лидерство, модели школьной эффективности); 
- научно-методическое руководство разработкой школьных программ перехода в эффективный режим работы и улучшения учебных результатов с приглашением специалистов и ученых ФГБОУ ВО «Алтайский государственный гуманитарнопедагогический университет им. В.М. Шукшина»;

- проведение входных, промежуточных мониторингов и оценка качественных и количественных результатов реализации мероприятий.

С целью повышению уровня квалификации педагогов, работающих в школах, находящихся в сложных социальных условиях, были реализованы следующие мероприятия:

- диагностика образовательных дефицитов обучающихся на основе данных результатов ГИА по предметным областям, независимой оценки, всероссийских проверочных работ, национальных и международных исследований, разработка и проведение комплекса мероприятий по их компенсации и коррекции с использованием образовательных технологий: Lesson Study, формирующее оценивание, критическое мышление и др.;

- проведение курсов и методических мероприятий по эффективному преподаванию в условиях работы с наиболее сложным контингентом;

- создание партнерства школ с высокими и низкими результатами обучения для совершенствования технологий преподавания и улучшения результатов обучения на основе функционирования сетевых площадок успешных практик, ассоциаций учителей-предметников и городских учебно-методических объединений по предметным областям и иных сетевых сообществ, в том числе с приглашением специалистов краевых ассоциаций и учебнометодических объединений;

- открытие «Школы эффективного учителя» ресурсных центров, представляющих собой базу лучших практик и направляющих свою деятельность на взаимодействие с руководителями школ с низкими образовательными результатами и учителями, испытывающими проблемы в преподавании, силами ассоциаций учителей-предметников города и региона;

- формирование среды для становления «успешного руководителя» и «эффективного учителя» через внедрение практик: наставничества (в том числе для молодых педагогов) [9], коучинга и менторской поддержки учителей, испытывающих проблемы в обучении школьников, взаимодействии с коллегами (networking), проблемы социально-психологического сопровождения деятельности учителя и ученика.

Важным механизмом в решении проблем школ с низкими образовательными результатами и перевода в эффективный режим функционирования является техническое оснащение образова- тельных организаций через получение широкого доступа в Интернет к хранилищам и базам данных, формирование единого образовательного пространства, обеспечение доступа учителей и учащихся к инновационным учебным пособиям и использованию интерактивных методов обучения. Следовательно, школы, работающие в трудных социальных условиях, должны получать специальную финансовую поддержку.

По итогам реализации программы управления деятельностью образовательных организаций, работающих в сложных социальных условиях, по переводу в эффективный режим функционирования была проведена повторная диагностика (метод статистического анализа кадровых, материально-технических условий, результатов независимых оценочных процедур ОГЭ, ЕГЭ), были получены следующие результаты:

- повышение качества образования, в том числе произошло увеличение среднего балла ОГЭ и ЕГЭ по основным предметам (русский язык и математика);

- улучшение материально-технической базы школ (увеличение показателей «Количество экземпляров учебной литературы в расчете на одного обучающегося», «Количество компьютеров в расчете на 1 обучающегося»);

- улучшение социального положения обучающихся, находящихся в «группе риска» (снижение количество семей и обучающихся, состоящих на различных видах профилактического учета);

- появление в муниципальной системе образования успешных практик перевода школ, работающих в сложных социальных условиях и показывающих низкие образовательные результаты, в эффективный режим функционирования;

- появление в муниципальной системе образования группы руководителей общеобразовательных организаций - консультантов по вопросам школьного посткризисного стратегического планирования и перевода общеобразовательных организаций в эффективный режим функционирования.

Таким образом, создание организационной инфраструктуры поддержки школ и учителей, работающих в сложных условиях, ориентация системы управления и деятельности образовательных организаций на образовательные достижения учащихся, организация межуровневого взаимодействия (муниципальные органы управления образованием, общеобразовательные организации, учреждения образования, социальные партнеры) способствуют переводу образовательных организаций с низкими образовательными результатами, находящихся в сложных социальных условиях, в эффективный режим функционирования. 


\section{Библиографический список}

1. Кравцов С. С. Основные направления развития общероссийской системы оценки качества образования // Народное образование. 2016. № 7/8. С. 9-16.

2. Уваров А. Г., Ястребов Г. А. Социально-экономическое положение семей и школа как конкурирующие факторы образовательных возможностей: ситуация в России // Мир России. 2014. № 2. С. 42-49.

3. Пинская М. А., Косарецкий С. Г., Фрумин И. Д. Школы, эффективно работающие в сложных социальных контекстах // Вопросы образования. 2011. № 4. С. 148-177.

4. Путин В. В. Строительство справедливости. Социальная политика для России. URL: https: / /vedtver.ru/news/ society/vladimir-putin-stroitel-stvo-spravedlivosti-social-naya-politika-dlya-rossii/ (дата обращения: 09.02.2021).

5. Кикоть О. П., Манузина Е. Б. Организация поддержки школ, работающих в сложных социальных условиях и показывающих низкие образовательные результаты // Развитие личности в образовательном пространстве: материалы XVI Всероссийской научно-практической конференции (Бийск, 18 мая 2018 г.) / отв. ред. Л. А. Мокрецова. Бийск: АГГПУ им. В. М. Шукшина, 2018. С. 23-26.

6. Пинская М. А., Косарецкий С. Г., Крутий Н. А. Учет контекстной информации при оценке качества работы школы // Народное образование. 2012. № 5. С. 31-35.

7. Пинская М. А., Ушаков К. М. Эффективная школа // Директор школы. 2014. № 7. С. 18-23.

8. Пинская М. А., Крутий Н. А., Косарецкий С. Г. Выравнивание условий при анализе достижений школ: контекстуализация результатов // Выравнивание шансов детей на качественное образование: сборник материалов. М.: Изд. дом ВШЭ, 2012. С. 37-47.

9. Манузина Е. Б. Готов ли современный выпускник педагогического вуза к работе в сельской школе, находящейся в сложных социальных условиях? // Развитие личности в образовательном пространстве: материалы XVIII Всероссийской с международным участием научно-практической конференции (Бийск, 21 мая 2020 г.) / отв. ред. Л. А. Мокрецова. Бийск: АГГПУ им. В.М. Шукшина, 2020. С. 141-144. 